\title{
Dr. Hugo Behm Rosas: un pionero de la medicina social (Santiago 1913 - San José 2011)
}

\author{
Dr. Hugo Behm Rosas: a pioneer in social medicine \\ (Santiago 1913 - San José 2011)
}

Molina Martínez, Gloria1; Gamboa De Bernardi, Rubén²; Novoa, Jocelyn³

\footnotetext{
${ }^{1}$ Psicóloga, Universidad de Chile. Especializada en el campo de las Ciencias Sociales y la salud. Ex consultora de la División de Desarrollo Social de la CEPAL. Consultora independiente, Chile.gloriamolina@mi.cl

2 Médico, Universidad de Chile. Especializado en Pediatría, Salud Pública y Epidemiología. Profesor asociado de Pediatría y Salud Pública, Universidad de Santiago de Chile. rubengamboa@gmail.com

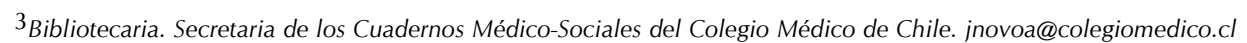

Después de obtener su título de médico cirujano en 1936, el Dr. Behm dedica los 17 años siguientes a la tisiología. En Santiago, como miembro del grupo médico del Hospital Sanatorio "El Peral", aporta numerosos trabajos clínicos y epidemiológicos, continuados después en un programa experimental de control de la tuberculosis en la comuna de Quinta Normal.

A partir de 1953, se dedica a la bioestadística, formándose a través de cursos especializados en la Escuela de Salubridad de Chile y en la Johns Hopkins University -formadora de otras figuras de la salud pública chilena-, profundizando posteriormente sus estudios en la Columbia University, en Nueva York.

Ese mismo año fue nombrado presidente de la Sociedad Chilena de Enfermedades Respiratorias, cargo que ejerció hasta 1954, desempeñándose al mismo tiempo como profesor de Bioestadística en la Escuela de Medicina de la Universidad de Chile, para luego ser director de la Escuela de Salubridad. Fue en ese período que el destacado epidemiólogo Milton Terris señaló que, junto a Johns Hopkins y a la Escuela de Salud Pública de Londres, la Escuela de Salubridad de la Universidad de Chile, dirigida por el Profesor Behm, constituían las tres mejores escuelas de salud pública del mundo.

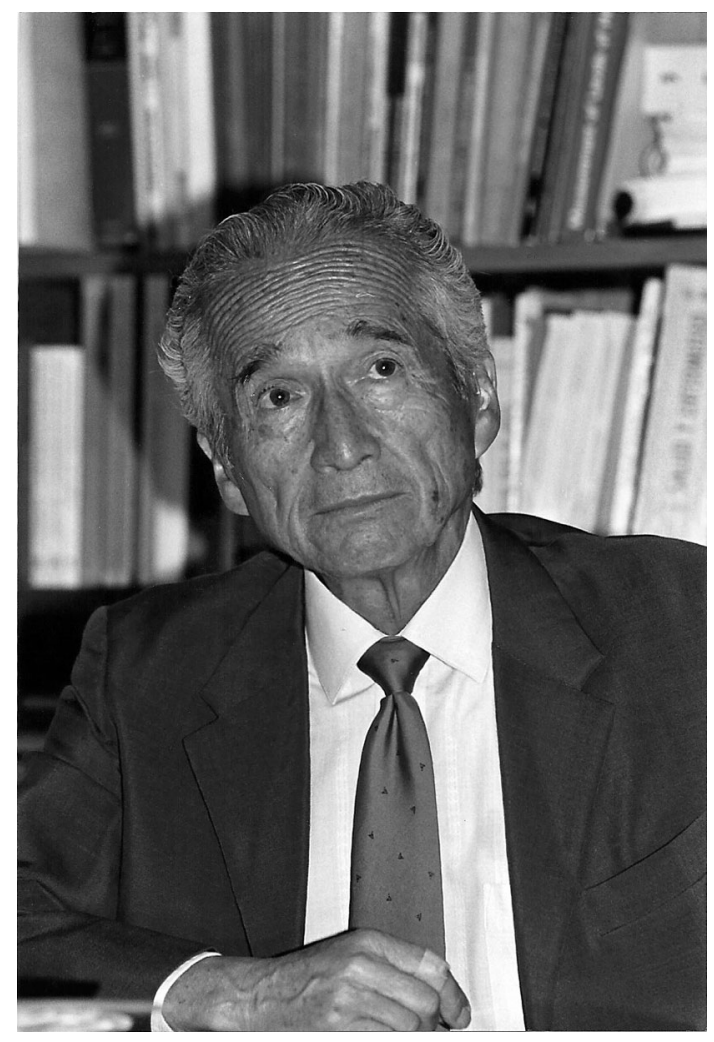

Además de sus grandes cualidades como organizador y director de la Escuela de Salubridad, se destacó por su mente ágil, la claridad de su pensamiento y la sencillez para enseñar una disciplina aparentemente difícil y árida como la bioestadística. 


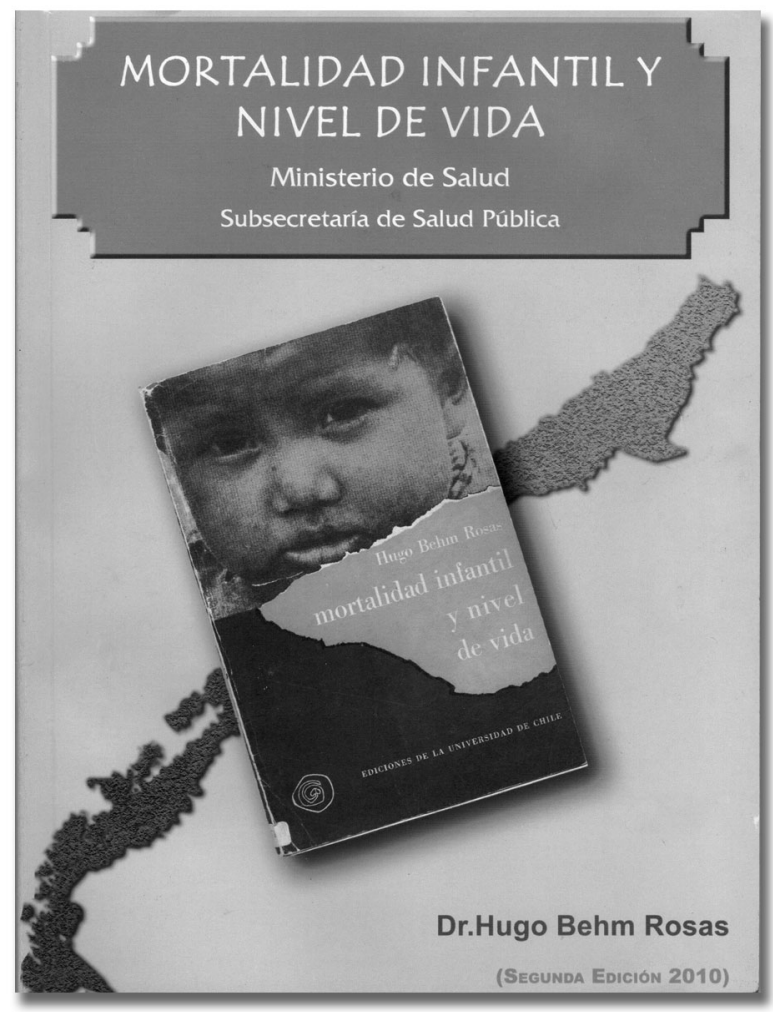

Ya a fines de la década del 40, era considerado como una de las personalidades de la salud pública chilena, a quien el entonces senador de la República, Salvador Allende, recurrió para dar forma a la ley que creó el Servicio Nacional de Salud en 1952, uno de los mejores proyectos para entregar una mejor salud a toda la población y modelo en Latinoamérica, solo homologable a los modelos existentes en ese momento en Gran Bretaña, Suecia y los países de la esfera soviética y que más tarde fue utilizado también como modelo para establecer el Sistema de Salud en Cuba. Este proyecto lamentablemente fue desmembrado completamente por el régimen militar de Augusto Pinochet.

A inicios de la década del 60, participa como socio fundador de la revista Cuadernos Médico Sociales, del Colegio Médico de Chile, destinada a ser órgano de las aspiraciones de salud de una sociedad en desarrollo y participa activamente en ella mientras vive en Chile.

En 1962, publica el libro Mortalidad infantil y nivel de vida bajo el alero de la Universidad de Chile. En este libro se presentó, por primera vez en Chile, un análisis estadístico que permitía discutir el alcance de las acciones médicas y de las acciones sociales en el control de la mortalidad infantil, en una población cuyo nivel de vida en ese entonces era muy bajo. Para muchos, este constituye el trabajo de investigación más importante del siglo XX en Chile.

Ese mismo año ingresa como consultor en la Organización Mundial de la Salud y en el Centro Latinoamericano de Demografía (CELADE) de la Comisión Económica para América Latina y el Caribe (CEPAL), en su especialidad de bioestadística, habiendo prestado asesorías en numerosos países latinoamericanos, en donde pasó a ser un referente en el campo de la salud pública.

En 1973 es hecho prisionero por el régimen militar. En septiembre de 1975 es trasladado desde el campo de concentración de Ritoque y expulsado del país, gracias a las gestiones realizadas por la Asociación Americana de Salud Pública (APHA) en pro de la liberación de seis trabajadores de la salud detenidos y encarcelados. Cabe señalar que el Dr. Behm detentaba el cargo de vicepresidente de APHA para América Latina, cargo para el cual es reelegido con posterioridad.

El actor chileno Oscar Castro, compañero de prisión del Dr. Behm, hizo llegar estas líneas a raíz de su muerte:

Este doctor que se preocupaba de la salud pública, marcó a todos los detenidos, su simpleza lo hizo ser un personaje inolvidable. Hablé varias veces de su pasión, una especialidad médica que yo pensaba hasta ese entonces, pertenecía a los especialistas de la burocracia. Me hablaba de lo importante que era que los pueblos crecieran sanos y que todos pudieran en buena salud, gozar de las posibilidades que da la vida.

En mi último viaje a Chile estuve con compañeros ex presidiarios y nos entretuvimos en recordar cada pieza del Campo de Concentración de Ritoque con los que ahí vivían, ya nos habíamos olvidado de muchas cosas, pero nos recordamos que de vez en cuando íbamos a ver al doctor no a consultarlo de una posible enfermedad, sino a compartir un té que, en su pieza, tenía la suerte de ser acompañado por una torreja de queque. Ahora que me anuncian su partida, lo único que me queda como reflexión es cómo un espíritu tan enorme, podía caber en un cuerpo como el de mi amigo el doctor Behm. Me despido con la 
serenidad de haber sabido a tiempo que otro gran amigo de infortunio ya nos dejó.

Durante su exilio, en Costa Rica, en su calidad de consultor del CELADE realiza un trabajo considerado pionero en el mundo sobre las desigualdades sociales en la mortalidad en Centroamérica, en Panamá y en América Latina. Los resultados de los estudios fueron demostrando de manera científica, país tras país, cómo la educación de las madres es un factor relevante para la salud y sobrevida de los hijos pequeños y, específicamente, en la disminución de la mortalidad infantil.

En carta dirigida a Ingrid, hija del Dr. Behm, Luis Bernardo Villalobos Solano, de la Escuela de Salud Pública de la Universidad de Costa Rica, recuerda su contribución:

Ayer al conocer la noticia del deceso de Don Hugo se me vino a la mente la imagen del orguIlo que tuve de conocer a tu padre, a quien ya admiraba porque había influido en mi formación como salubrista a principios de los 80 , en la Universidad de Antioquia en Medellín, Colombia. En esa Universidad, mi profesor, Alberto Vasco Uribe, también de grata memoria, nos recomendó un artículo que el Dr. Behm había publicado la Revista Centroamericana de Ciencias de la Salud, en enero de 1979, denominado: Determinantes Económicos y Sociales de la Mortalidad en América Latina.

Frecuentemente recuerdo con mis estudiantes de grado y de postgrado esta excelente publicación que se adelantó en el tiempo, antes que la Comisión presidida por Sir Michael Marmot presentara a la Organización Mundial de la Salud (OMS) en el 2008 el informe sobre los Determinantes Sociales de la Salud, ya Don Hugo hablaba del concepto de determinantes. Él se había adelantado 32 años, aunque creo que muchísimos más, porque cuando las ideas se plasman con tanta claridad en un escrito es porque se ha investigado -como en este caso- y se tiene la experiencia de varias décadas.

Deseo recordar a todos los que caminamos por estos rumbos de la Salud Pública, promoviendo una sociedad más justa y equitativa, lo que nos decía Don Hugo al iniciar su artículo (cito textual):
"La mortalidad en América Latina ha experimentado notorios descensos en décadas recientes, pero tiene aún claros excesos sobre los niveles alcanzados en regiones más avanzadas. La relación de la muerte con las condiciones socioeconómicas es bien conocida, aunque el modo de acción y el peso relativo de los diversos factores intervinientes es asunto no bien dilucidado. Es conveniente, pues, analizar el conocimiento que existe sobre las características y la génesis de los diferenciales socioeconómicos de la mortalidad en América Latina, para explicar mejor la situación actual y sus perspectivas."

Creo que la lectura reposada de este y otros trabajos matizados en el contexto actual, sin duda seguirán aportando a lo que Don Hugo plantea al final de este artículo al realizar una alusión de lo que expone Antonovsky con la estratificación de la proporción de muertes que se dieron en el hundimiento del Titanic según la clase en la que viajaban en esa nave, siendo por supuesto los más perjudicados los de la "tercera clase", con lo que sucede en América Latina. Cito de nuevo:

"Anualmente se echan por su borda casi un millón de cadáveres de niños de cinco años, que todo hace pensar que no debieran morir, y que provienen en su mayoría de la "tercera clase". Nuestra responsabilidad es mostrar, a los niveles políticos de decisión y a los pueblos mismos, de modo objetivo y con las armas que nos da la ciencia, la magnitud de ese monstruoso genocidio y las causas profundas que lo originan."

Hoy, esto sigue vigente con otra connotación, puesto que la niñez se muere menos antes de los cinco años, pero después de esa edad y hasta su vejez, cuando escapan de morir siendo adolescentes o jóvenes, se van muriendo poco a poco de los estragos que apuntaba Don Hugo.

El premio anual del International Health Central American Institute (IHCAI) lleva el nombre de este humanista, estadístico y epidemiólogo de América Latina que dedicó su vida a la lucha contra la mortalidad infantil.

El muy querido Dr. Hugo Behm Rosas falleció el jueves 28 de abril de 2011 a las 3:50 de la madrugada en San José de Costa Rica. 
La obra del profesor Behm es reconocida a nivel mundial, siendo una fuente de inspiración en el mundo de la salud pública y la medicina social para muchas generaciones de médicos.

Entre los numerosos trabajos publicados sobre la materia, se destacan:

- Behm H, Rosero L. La mortalidad en los primeros años de vida en América Latina. San José: CELADE; 1977.

- Behm H. Determinantes económicos y sociales de la mortalidad infantil en América
Latina. Revista Centroamericana de Ciencias de la Salud. 1979;(12):69-102.

- Behm Rosas H. La mortalidad en la niñez en Centroamérica, Panamá y Belice 1970-1985. San José: CELADE; 1988.

- Behm H. Las desigualdades sociales ante la muerte en América Latina. San José: CELADE, Organización Holandesa para la Cooperación Internacional en Educación Superior; 1992.

\section{FORMA DE CITAR}

Molina Martínez G, Gamboa De Bernardi R, Novoa J. Dr. Hugo Behm Rosas: un pionero de la medicina social. (Santiago 1913 - San José 2011). Salud Colectiva. 2011;7(2):255-258. 